EGU2020-15880

https://doi.org/10.5194/egusphere-egu2020-15880

EGU General Assembly 2020

(c) Author(s) 2020. This work is distributed under

the Creative Commons Attribution 4.0 License.

\title{
Assessment of magnetic data for landfill characterization by means of a probabilistic approach
}

\author{
Itzel Isunza Manrique ${ }^{1}$, David Caterina ${ }^{1}$, Cornelia Inauen ${ }^{2}$, Arnaud Watlet ${ }^{2}$, Ben Dashwood ${ }^{2}$, Tom \\ Debouny ${ }^{1}$, Thomas Hermans ${ }^{3}$, and Frederic Nguyen ${ }^{1}$ \\ ${ }^{1}$ University of Liege, Urban and Environmental Engineering, Belgium (iisunza@uliege.be) \\ ${ }^{2}$ British Geological Survey, Environmental Science Centre, Nottingham, UK \\ ${ }^{3}$ Geology Department, Ghent University, Ghent, Belgium
}

The sustainable vision of the Dynamic Landfill Management (DLM) deals not only with present but also with long-term waste management. In this context, DLM enhances the environmental assessment of landfills after closure as well as the recovery of materials and energy resources, for which, a proper characterization is required. To this end, geophysical methods have demonstrated their suitability for landfill exploration, characterization and monitoring. Due to the complexity of these sites and challenges in data acquisition and/or processing, the use of multiple methods is the best approach for landfill investigations. In this work, we used multiple geophysical methods, co-located with several trial pits and boreholes, to estimate the structure of a waste disposal site located in a quarry, and to better delineate the underlying geology composed of limestone. We applied electrical resistivity tomography (ERT), time-domain induced polarization (IP), H/V spectral ratio from microtremor records and magnetometry. We made a structural joint interpretation using the different datasets and the ground truth data. First, the ERT and IP data were individually inverted, and a first structural model was derived. Afterwards, we followed a parametric analysis of the $\mathrm{H} / \mathrm{V}$ data to corroborate the thickness of some layers at the position of the seismic stations. Then, this model was used to compute synthetic magnetic data and by comparing them with the observed total field magnetic anomalies, a refined model was produced. We evaluated the improvement of including magnetic modelling by using a probabilistic approach previously reported. This approach is based on the computation of conditional probabilities by comparing the inverted models with the co-located data from trial pits and boreholes. Overall, we delineated the lateral and vertical extension of the waste body, the distribution of ash and lime deposits and estimated the upper limit structure of the bedrock.

How to cite: Isunza Manrique, I., Caterina, D., Inauen, C., Watlet, A., Dashwood, B., Debouny, T., Hermans, T., and Nguyen, F.: Assessment of magnetic data for landfill characterization by means of a probabilistic approach, EGU General Assembly 2020, Online, 4-8 May 2020, EGU2020-15880, https://doi.org/10.5194/egusphere-egu2020-15880, 2020 